\title{
Plasmodium vivax malaria in a Romanian traveller returning from Greece, August 2011
}

S A Florescu ${ }^{1,2}$, C P Popescu ${ }^{1,2,3}$, P Calistru ${ }^{1,2}$, E Ceausu $^{1,2}$, M Nica $^{1,2}$, A Toderan $^{1}$, M Zaharia $^{1}$, P Parola (philippe.parola@univmed.fr) ${ }^{3,4,5}$

1. 'Carol Davila' University of Medicine and Pharmacy, Bucharest, Romania

2. 'Dr Victor Babes' Hospital for Infectious and Tropical Diseases, Bucharest, Romania

3. EuroTravNet, European Travel and Tropical Medicine Network, European Centre for Disease Prevention and Control (ECDC), Stockholm, Sweden

4. GeoSentinel, the Global Surveillance Network of the International Society of Travel Medicine (ISTM) and the Centers for Disease Control and Prevention (CDC)

5. Faculty of Medicine, Aix-Marseille University, Marseille, France

Citation style for this article:

Florescu SA, Popescu CP, Calistru P, Ceausu E, Nica M, Toderan A, Zaharia M, Parola P. Plasmodium vivax malaria in a Romanian traveller returning from Greece, Florescu SA, Por

Euro Surveill. 2011;16(35):pii=19954. Available online: http://www.eurosurveillance.org/ViewArticle.aspx?Articleld=19954

Article published on 1 September 2011

In August 2011, a Plasmodium vivax malaria infection was diagnosed in a Romanian traveller returning from Greece. This case together with several reports over the past decade of autochthonous cases in Greece highlight that malaria should be considered as differential diagnosis in symptomatic travellers returning from this country. Travellers may serve as sentinels of emerging vector-borne diseases.

Malaria is considered to be eradicated in several European countries since 1975, although Anopheles spp. mosquito vectors remain prevalent in parts of southern and central Europe [1]. A few cases of autochthonous transmission of malaria to local residents have been reported over the last 10 years in areas where the disease has been declared eradicated (Bulgaria, France, Germany, Greece, Italy, and Spain), including the so-called airport malaria, but there has not been sustained local transmission in any specific location [2].

In this report, we describe a case of malaria in a Romanian traveller returning from Greece.

\section{Case report}

On 1 August 2011, a 25-year-old Romanian man developed an acute febrile illness with chills, myalgia, fever, and left abdominal flank pain. He had returned from Greece on 30 July. His past medical history included a splenectomy 14 years earlier. As the symptoms persisted, on 3 August, the patient visited the family doctor who suspected a respiratory infection and prescribed a symptomatic and antibiotic treatment (amoxicillin-clavulanate). On 9 August, as there was no improvement in his symptoms, as the fever persisted and he felt an increased pain in the left flank, and after an episode of near syncope, he was admitted to the local hospital in his area of residence. Abdominal ultrasound showed a hematoma in the splenic bed ( 5.5 by $6.6 \mathrm{~cm})$. The hematoma was surgically drained. On 11
August laboratory results revealed thrombocytopenia (57,000/mm3 ; norm: 150,000-400,000), anaemia $(\mathrm{Hb}$ : $8.7 \mathrm{~g} / \mathrm{dl}$; norm 11.5-15), and leukocytosis $\left(16,600 / \mathrm{mm}^{3}\right.$; norm: 4,000-10,000) with normal white blood cell differential count. Blood cultures taken upon each hospital admission remained negative. Thin blood smear revealed Plasmodium spp. trophozoites and schizonts. On the same day, the patient was transferred to 'Victor Babes' Hospital for Infectious and Tropical Diseases in Bucharest. On arrival, physical examination revealed a reduced general condition, a temperature of $37.8^{\circ} \mathrm{C}$, abdomen with diffuse sensitivity to palpation, and moderate hepatomegaly. Thin and thick films revealed Plasmodium vivax parasitaemia of $0.05 \%$ with mature trophozoites, young schizonts, and gametocytes of $P$. Vivax. Whole blood DNA quantification using a LightScanner 32 (Idaho Technology, USA) demonstrated $P$. Vivax $(1,500$ copies/ $\mu l)$ and was negative for the other Plasmodium species. The patient responded quickly to the seven-day treatment of oral quinine combined with doxycycline. The clinical response was good (fever ceased after 48 hours of treatment) and the parasite clearance appropriate (negative thin and thick smear after 72 hours of antiparasitic treatment). After this treatment, the patient was given primaquine for 14 days to prevent relapses.

Patient history revealed that he had worked intermittently in agriculture in Greece, for about six years (in 2005 in Argos region and then every October to February from 2006 to 2010 in Lakonia region, in Skala and Elos localities of the Evrotas river basin). More recently, from November 2010 to 30 July 2011 he worked in the same regions (Skala and Elos) in agriculture. He had no history of travel to any malaria-endemic areas and his only other travel abroad was a two-month trip to Italy (Sicily) from September to October 2010. He had never travelled by plane, he does not live in the proximity of any international airport and there have been no reports of imported malaria cases within his residence 
area in Romania. Malaria tests in the patient's relatives with whom he had travelled and worked in Greece were negative.

\section{Epidemiological situation in Greece}

Several Anopheline vector species are known to breed in Greece, including some of the historically most important vectors in Europe including $A$. atroparvus, $A$. sacharovi and $A$. superpictus that are competent for P. Vivax [3]. As early as 1994 and 1995 four autochthonous malaria cases ( $P$. falciparum, $P$. malariae and two $P$. Vivax) were diagnosed in Evros, northern Greece, in native residents from rural areas who stated that they had never left Greece or visited an international airport [4]. In the summer of 1998 two additional malaria cases ( $P$. Vivax) were diagnosed in the same region in two patients who had been living for four years in Feres (in the Evros peripheral area, East Macedonia and Thrace, Greece) after they had immigrated from southern Albania [5]. Later, an autochthonous cluster of $P$. Vivax malaria occurred in the Evrotas river basin, Lakonia, southern Greece, from August to October 2009, with eight patients hospitalised in Sparta General Hospital, including two immigrants from Pakistan and Afghanistan and six patients, natives of Lakonia and living in different areas from the first two [6]. More recently, between June and 18 August 2011, six cases of locally-acquired $P$. Vivax malaria have been notified to the Hellenic Centre for Disease Control and Prevention through the mandatory notification system in Greece: four cases from the same agricultural wetland area of the Evrotas river basin, Lakonia, in the Peloponnese, southern Greece and two cases who reside near the city of Chalkida, Evoia, in the eastern part of Greece [7]. All cases were local residents with no history of travel to a malaria endemic area.

\section{Epidemiological situation in Romania}

The $P$. Vivax malaria case in Romania was reported to the National Institute of Public Health within the National Malaria Surveillance Programme. In Romania, there is a national programme for surveillance and rapid communication of malaria cases. In 1948, a total of 333,198 cases of malaria were reported, but starting with 1968 Romania was declared a malaria-free country. No local transmission of malaria has been reported in Romania since then. Nevertheless, malaria remains a possible re-emerging disease especially in the southern and south-eastern part of the country, where vector-competent Anopheles species are prevalent [8]. In the past 10 years, 107 cases of malaria were diagnosed in the 'Victor Babes' Hospital of Infectious and Tropical Diseases in Bucharest and all of them were in travellers who had returned from malaria endemic areas, mostly from Africa $[9,10]$.

\section{Discussion and conclusions}

The occurrence of presumably vector-competent Anopheles species, together with increasingly favourable climatic conditions and the frequent availability of reservoirs of infection such as imported cases, produce an ongoing probability of autochthonous malaria appearing time and again.

This case report presented epidemiological evidence and patient history point to an infection in the Skala and Elos areas Greece. Prior to 2011, the patient had not been exposed in Greece during summer, or during periods when autochthonous cases were reported in Greece. However, it is unclear whether the reservoir of infection for this case was from migrant workers in Greece coming from South Asia or from the local population.

To the best of our knowledge, this is the second case of malaria reported recently in an international traveller who acquired the infection in an European Union (EU) country. In 2000, a German couple was diagnosed almost simultaneously with $P$. Vivax malaria after a one-week holiday in Kassandra, Chalkidiki, a Greek tourist resort [11]. No local cases had been reported at that time but it seems that sporadic local transmission must have been occurring.

Since Greece is a frequent destination for people visiting or working, any re-emergence of malaria will be of concern. Furthermore, the occurrence of malaria cases in areas considered to be malaria-free may lead to delay in diagnosis raising the possibility of exposure to vectors and even the risk of incidence of local malaria cases.

To date, there has been no recommendation for travellers to the affected areas in Greece to take any antimalarial chemoprophylactic drug. However, advice has been issued on avoidance measures regarding insect bites particularly during the evening and at night $[12,13]$.

In the authors' opinion, the Greek interventions with the current cases should be followed closely so that Romania and other formerly malaria endemic countries in the EU remain malaria-free. Both local health authorities and practicing clinicians need to be aware that they should also include malaria in the differential diagnosis in travellers and temporary residents returning from Greece and maybe also other southern European countries. However, according to a risk assessment related to the six autochthonous cases of $P$. Vivax malaria in Greece, published by the European Centre for Disease Prevention and Control, the risk for further extension of malaria transmission into the EU is considered low at present [7].

Acknowledgments

We are grateful to Prof. David O. Freedman from GeoSentinel and Jørgen Eskild Petersen for helpful discussions. 


\section{References}

1. World Health Organization Regional Office for Europe (WHO Europe). Regional Strategy: the Move from Malaria Contro to Elimination in the WHO European Region 2006-2015. Copenhagen: WHO Europe. 2006. [Accessed 31 Aug 2011]. Available from: http://www.euro.who.int/_data/assets/pdf_ file/0011/98750/E88840.pdf

2. European Centre for Disease Prevention and Control (ECDC). Annual epidemiological report on communicable diseases in Europe - 2010. Stockholm: ECDC. 2010. [Accessed 26 Aug 2011]. Available from: http://ecdc.europa.eu/en/publications/ Publications/1011_SUR_Annual_Epidemiological_Report_on_ Communicable Diseases in Europe.pdf

3. Kampen H, Proft J, Etti S, Maltezos E, Pagonaki M, Maier WA, et al. Individual cases of autochthonous malaria in Evros Province, northern Greece: entomological aspects. Parasitol Res. 2003;89(4):252-8

4. Maltezos E, Cristakidis D, Nikolaidis-Eugenidis P, Gotsis N. Autochthonous malaria in Evros, Greece, during the last two years. Med Educ. 1995;3:41-52.

5. Kampen H, Maltezos E, Pagonaki M, Hunfeld KP, Maier WA, Seitz HM. Individual cases of autochthonous malaria in Evros Province, northern Greece: serological aspects. Parasitol Res. 2002;88(3):261-6.

6. Andriopoulos P, Oikonomopoulou A, Rigaki K, Kaplanis N, Rebelou D, Assimakopoulos G. An outbreak of Plasmodium vivax malaria in Lakonia, southern Greece, August-October 2009. Abstracts 2oth European Congress of Clinical Microbiology and Infectious Diseases (ESCMID). Vienna. 10-13 April 2010.

7. European Centre for Disease Prevention and Control (ECDC). Risk assessment: Autochthonous Plasmodium vivax malaria in Greece. Stockholm: ECDC. 2010. [Accessed 23 Aug 2011]. Available from: http://ecdc.europa.eu/en/publications/ Publications/110823_TER_Risk_Assessment_Malaria_Greece. pdf

8. Nicolescu G, Linton YM, Vladimirescu A, Howard TM, Harbach RE. Mosquitoes of the Anopheles maculipennis group (Diptera: Culicidae) in Romania, with the discovery and formal recognition of a new species based on molecular and morphological evidence. Bull Entomol Res. 2004;94(6):525-35.

9. Florescu SA, Popescu CP, Ceausu E, Calistru PI. Imported Tropical Diseases in Romania - Last 10 years. 3rd Northern Conference on Travel Medicine (NECTM). Hamburg. 26 29 May 2010. [Accessed 26 Aug 2011]. Available from: http://nectm.com/wp-content/uploads/file/2010\%20 OnlineProgramme\&Abstracts.pdf

10. Florescu S, Ceausu E, Calistru P, Voinea C, Turcu Mozes E, Nica $M$, et al. Imported tropical pathology in Romania in the last 11 years. Ro J Infect Dis. 2010;13(1):11-15. Romanian.

11. ProMED-mail. Malaria, Vivax - Germany ex Greece. Archive Number 20000713.1158. 13 Jul 2000. Available from: http:// www.promedmail.org

12. Centers for Disease Control and Prevention (CDC). Malaria cases: Greece. Atlanta: CDC. [Accessed 26 Aug 2011]. Available from: http://wwwnc.cdc.gov/travel/news-announcements/ malaria-greece.htm

13. National Travel Health Network and Centre (NaTHNaC).

Malaria: Prefectures of Lakonia (Peloponnese) and Evoia (Euboea), Greece. London: NaTHNaC. 23 Aug 2011. Available from: http://www.nathnac.org/pro/clinical_updates/malaria Greece_230811.htm 